\title{
Trajectory Tracking with Input Constraint Based on Linear Matrix Inequalities Approach of A Nonholonomic Mobile Robot
}

\author{
Auliya Nabila \\ Department of Electrical Engineering \\ Institut Teknologi Sepuluh Nopember \\ Surabaya, Indonesia \\ auliyanabilaa@gmail.com
}

\author{
Trihastuti Agustinah \\ Department of Computer Engineering \\ Institut Teknologi Sepuluh Nopember \\ Surabaya, Indonesia \\ trihastuti@ee.its.ac.id
}

\begin{abstract}
Nonholonomic Mobile Robot (NMR) is a mode of transportation that is widely used in industry. NMR is driven by an actuator with limited torque which magnitude of control signal is always limited. To solve this problem two controllers were designed, i.e. kinematic controller and dynamic controller. A kinematic controller is designed so that the additional speed converges to the desired speed, while the dynamic controller is designed using $H_{\infty}$ performance to overcome the control signal constraints. State-feedback gain of the dynamics controller is obtained using Linear Matrix Inequalities (LMI) approach. Simulation results show that the designed controllers can perform tracking according to the reference trajectory with the magnitude of torques are less than $\pm 0.6 \mathrm{Nm}$ and the tracking error is $0.009 \mathrm{~m}$ in the presence input constraint and external disturbance.
\end{abstract}

Keywords-NMR, input constraint, $H_{\infty}$ performance, linear matrix inequalities

\section{INTRODUCTION}

The use of nonholonomic mobile robot (NMR) technology has been widely used for various purposes. Several studies on NMR have been carried out, including research on the stability of mobile robots [1], trajectory tracking of mobile robots [2], and robustness of mobile robots to external and internal disturbances [3].

Many control methods are used to solve control problems in NMR, such as sliding mode controller [4] and time-varying controller [5]. A sliding mode controller is used for trajectory tracking by considering the kinematic model of the mobile robot. Meanwhile, the time-varying controller is designed using the Lyapunov approach to solve the problems of stability and tracking in NMR. The simulation results show that NMR can perform tracking with the tracking error converges to zero.

In its application, the dynamic model of NMR cannot be ignored in the control so that in [6] a nonlinear control method with saturation constraint is used. In [7], Linear Active Disturbance (LADRC) and Extended State Observer (ESO) algorithms are used to solve the problem of input constraints given to the system. NMR is driven by an actuator with limited torque so that the magnitude of the control signal is always limited. System performance which is often limited causes the system to become unstable [8,9], so that the development of adaptive control schemes for mobile robots with input constraints is an interesting research to do.

Stability and tracking problems of mobile robot with input (control signal) constraints and external disturbances are discussed in [10]. The application of the proposed method is more complicated, so that the resulting trajectory tracking cannot follow the reference trajectory due to the input constraints. To overcome this input constraints, $H_{\infty}$ performance is used and Lyapunov inequality is solved by Linear Matrix Inequalities optimization so that the state-feedback gain can be obtained [11]. The simulation results show that the mobile robot can perform tracking according to the reference trajectory.

Based on the various problems and solution above, this study uses two controllers, namely kinematic controller and dynamic controller. The kinematic controller is designed so that the additional speed converges to the desired speed. Dynamic controller is designed using $H_{\infty}$ performance to overcome the input constraint and the Lyapunov inequality is solved by Linear Matrix Inequalities so that statefeedback gain can be obtained with given input constraint.

\section{MethodS}

Many approaches of Multiple Object Tracking (MOT) have a common strategy, the first step is detecting object

\section{A. Nonholonomic Mobile Robot Model}

The nonholonomic mobile robot (NMR) model is illustrated in Fig. 1. The geometrical center is denoted by $\mathrm{C}$, the mass center is denoted by A, $\theta$ is the angle of moving robot to the frame, $\left[\begin{array}{ll}x_{m} & y_{m}\end{array}\right]$ denotes the cartesian axis representing the robot to frame, $a$ is the distance between the center of mass and driving wheels, $2 R a$ is wheel diameter, and $2 L$ is the distance between wheels.

The NMR model is as follows [10]:

$$
\begin{aligned}
& \dot{\mathrm{q}}=\mathrm{S}(\mathrm{q}) \mathrm{v}_{\mathrm{a}} \\
& \mathrm{M}(\mathrm{q}) \ddot{\mathrm{q}}+\mathrm{V}(\mathrm{q}, \dot{\mathrm{q}})=\mathrm{B}(\mathrm{q}) \tau-\mathrm{A}^{\mathrm{T}}(\mathrm{q}) \lambda
\end{aligned}
$$

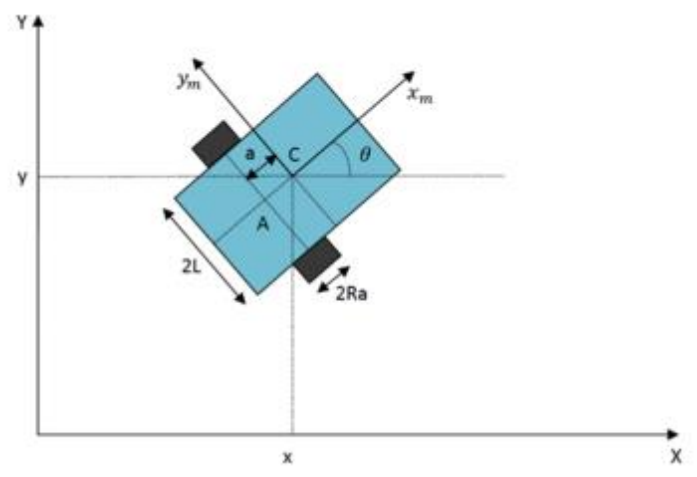

Fig. 1. Model of NMR 
where $\dot{\mathrm{q}}$ denotes the position and orientation of the robot, $v_{a}$ is the velocity of the robot in the local frame, $M(q) \ddot{q}$ is the system inertia matrix, $V(q, \dot{q})$ is the centripetal and coriolis matrix, $\mathrm{B}(\mathrm{q})$ is the input transformation matrix, $\tau=\left[\begin{array}{ll}\tau_{1} & \tau_{2}\end{array}\right]^{\mathrm{T}}$ denotes the control torques of the robot, $A^{T}(q)$ is the constraints matrix, and $\lambda$ is the vector of the constraint forces. $S(q), M(q), V(q, \dot{q})$, $B(q), A^{T}(q)$, and $\lambda$ are given as follows:

$$
\begin{aligned}
& S(q)=\left[\begin{array}{cc}
\cos \theta & -a \sin \theta \\
\sin \theta & a \cos \theta \\
0 & 1
\end{array}\right] \\
& M(q)=\left[\begin{array}{ccc}
m & m a \sin \theta \\
0 & m & -m a \cos \theta \\
m a \sin \theta & -m a \cos \theta & I_{c}+2 m a^{2}
\end{array}\right] \\
& V(q, \dot{q})=\left[\begin{array}{cc}
m a \dot{\theta}^{2} & \cos \theta \\
m a \dot{\theta}^{2} & \sin \theta \\
0 &
\end{array}\right] \\
& B(q)=\frac{1}{R_{a}}\left[\begin{array}{cc}
\cos \theta & \cos \theta \\
\sin \theta & \sin \theta \\
L & -L
\end{array}\right] \\
& A^{T}(q)=\left[\begin{array}{cc}
-\sin \theta \\
\cos \theta \\
-a
\end{array}\right] \\
& \lambda=-m\left(\dot{x}_{c} \cos \theta+\dot{y}_{c} \sin \theta\right) \dot{\theta}
\end{aligned}
$$

where $\mathrm{m}$ is the total mass of robot and $\mathrm{I}_{\mathrm{c}}$ is the inertia moment of robot.

The differentiate of equation (1) can obtain:

$$
\ddot{\mathrm{q}}=\dot{\mathrm{S}}(\mathrm{q}) \mathrm{v}_{\mathrm{a}}+\mathrm{S}(\mathrm{q}) \dot{\mathrm{v}}_{\mathrm{a}}
$$

Substituting (3) to (2) yields

$$
\overline{\mathrm{M}}(\mathrm{q}) \dot{\mathrm{v}}_{\mathrm{a}}(\mathrm{t})+\overline{\mathrm{V}}_{\mathrm{m}}(\mathrm{q}, \dot{\mathrm{q}}) \mathrm{v}_{\mathrm{a}}(\mathrm{t})=\overline{\mathrm{B}}(\mathrm{q}) \tau
$$

where,

$$
\begin{aligned}
& \overline{\mathrm{M}}(\mathrm{q})=\left[\begin{array}{cc}
\mathrm{m} & 0 \\
0 & \mathrm{I}_{\mathrm{c}}+\mathrm{ma}^{2}
\end{array}\right] \\
& \overline{\mathrm{V}}_{\mathrm{m}}(\mathrm{q}, \dot{\mathrm{q}})=\left[\begin{array}{cc}
0 & -\mathrm{ma} \dot{\theta} \\
\mathrm{ma} \dot{\theta} & 0
\end{array}\right] \\
& \overline{\mathrm{B}}(\mathrm{q})=\frac{1}{\mathrm{R}_{\mathrm{a}}}\left[\begin{array}{cc}
1 & 1 \\
\mathrm{~L} & -\mathrm{L}
\end{array}\right] \tau
\end{aligned}
$$

\section{B. Controller Design}

The trajectory tracking control system is designed to keep the position and orientation of NMR on the desired trajectory (Fig. 2). The kinematic controller is designed so that the additional speed converges to the desired speed and the dynamic controller is designed based on $H_{\infty}$ performance to overcome the input constraint. Linear Matrix Inequalities approach is used to solve the inequality to obtain the state-feedback gain. This enables us to make the bound of the input constraint as a function of design parameter. In this way, we can compute the bound and ensure it within the limit by suitably choosing the design parameters. Therefore with these parameters, input constraint is the same as $\tau$ and the derived design law for input constraint is also the control law for $\tau$.

\section{1) Kinematic Controller}

Let there be a prescribed reference trajectory:

$$
\begin{aligned}
& \dot{\mathrm{x}}_{\mathrm{r}}=\mathrm{v}_{\mathrm{r}} \cos \theta_{\mathrm{r}} \\
& \dot{\mathrm{y}}_{\mathrm{r}}=\mathrm{v}_{\mathrm{r}} \sin \theta_{\mathrm{r}} \\
& \dot{\theta}_{\mathrm{r}}=\omega_{\mathrm{r}}
\end{aligned}
$$

where $v_{r}$ is the desired linear velocity, $\omega_{r}$ is the angular velocity of robot, and $\left(\mathrm{x}_{\mathrm{r}}, \mathrm{y}_{\mathrm{r}}, \theta_{\mathrm{r}}\right)$ is desired reference of robot.

The tracking error is defined as,

$$
\left[\begin{array}{l}
\mathrm{x}_{\mathrm{e}} \\
\mathrm{y}_{\mathrm{e}} \\
\theta_{\mathrm{e}}
\end{array}\right]=\left[\begin{array}{ccc}
\cos \theta & \sin \theta & 0 \\
-\sin \theta & \cos \theta & 0 \\
0 & 0 & 1
\end{array}\right]\left[\begin{array}{l}
\mathrm{x}_{\mathrm{r}}-\mathrm{x} \\
\mathrm{y}_{\mathrm{r}}-\mathrm{y} \\
\theta_{\mathrm{r}}-\theta
\end{array}\right]
$$

The tracking error vector using (6) as follows:

$$
\begin{aligned}
\dot{\mathrm{x}}_{\mathrm{e}}= & \left(\dot{\mathrm{x}}_{\mathrm{r}}-\mathrm{x}\right) \cos \theta+\left(\dot{\mathrm{y}}_{\mathrm{r}}-\mathrm{y}\right) \sin \theta-\left(\mathrm{x}_{\mathrm{r}}-\right. \\
& \mathrm{x}) \dot{\theta} \sin \theta+\left(\mathrm{y}_{\mathrm{r}}-\mathrm{y}\right) \dot{\theta} \cos \theta \\
= & \mathrm{x}_{\mathrm{e}} \omega-\mathrm{v}+\dot{\mathrm{x}}_{\mathrm{r}} \cos \left(\theta_{\mathrm{r}}-\theta\right)+\dot{\mathrm{y}}_{\mathrm{r}} \sin \left(\theta_{\mathrm{r}}-\theta\right) \\
= & \mathrm{e}_{\mathrm{y}} \omega-\mathrm{v}+\mathrm{v}_{\mathrm{r}} \cos \theta_{\mathrm{e}} \\
\dot{\mathrm{y}}_{\mathrm{e}}= & -\left(\dot{\mathrm{x}}_{\mathrm{r}}-\dot{\mathrm{x}}\right) \sin \theta+\left(\dot{\mathrm{y}}_{\mathrm{r}}-\dot{\mathrm{y}}\right) \cos \theta-\left(\mathrm{x}_{\mathrm{r}}-\right. \\
& \mathrm{x}) \dot{\theta} \cos \theta-\left(\mathrm{y}_{\mathrm{r}}-\mathrm{y}\right) \dot{\theta} \sin \theta \\
= & \mathrm{x}_{\mathrm{e}} \omega-\dot{\mathrm{x}}_{\mathrm{r}} \sin \left(\theta_{\mathrm{r}}-\theta\right)+\dot{\mathrm{y}}_{\mathrm{r}} \cos \left(\theta_{\mathrm{r}}-\theta\right) \\
= & -\mathrm{x}_{\mathrm{e}} \omega+\mathrm{v}_{\mathrm{r}} \sin \theta_{\mathrm{e}} \\
\dot{\theta}_{\mathrm{e}}= & \dot{\theta}_{\mathrm{r}}-\dot{\theta}=\omega_{\mathrm{r}}-\omega
\end{aligned}
$$

From (7), after some manipulation we have

$$
\left[\begin{array}{c}
\dot{x}_{\mathrm{e}} \\
\dot{\mathrm{y}}_{\mathrm{e}} \\
\dot{\theta}_{\mathrm{e}}
\end{array}\right]=\left[\begin{array}{c}
\mathrm{v}_{\mathrm{r}} \cos \theta_{\mathrm{e}}-\mathrm{v}+\omega \mathrm{y}_{\mathrm{e}} \\
\mathrm{v}_{\mathrm{r}} \sin \theta_{\mathrm{e}}-\omega \mathrm{x}_{\mathrm{e}} \\
\omega_{\mathrm{r}}-\omega
\end{array}\right]
$$

To design the control input, we consider the following Lyapunov function:

$$
\mathrm{V}_{1}=\frac{1}{2}\left(\mathrm{x}_{\mathrm{e}}^{2}+\mathrm{y}_{\mathrm{e}}{ }^{2}\right)+\frac{\left(1-\cos \mathrm{y}_{\mathrm{e}}\right)}{\mathrm{K}_{\mathrm{y}}}
$$

where $\mathrm{K}_{\mathrm{y}}$ is a positive constant.

Differentiating $V_{1}$ along the trajectories of (6) leads to

$$
\begin{aligned}
\dot{\mathrm{V}}_{1}= & \dot{\mathrm{x}}_{\mathrm{e}} \mathrm{x}_{\mathrm{e}}+\dot{\mathrm{y}}_{\mathrm{e}} \mathrm{y}_{\mathrm{e}}+\frac{\dot{\theta}_{\mathrm{e}} \sin \theta_{\mathrm{e}}}{\mathrm{K}_{\mathrm{y}}} \\
= & {\left[\left(\omega_{\mathrm{r}}+\mathrm{v}_{\mathrm{r}}\left(\mathrm{K}_{\mathrm{y}} \mathrm{y}_{\mathrm{e}}+\mathrm{K}_{\theta} \sin \theta_{\mathrm{e}}\right)\right) \mathrm{y}_{\mathrm{e}}-\mathrm{K}_{\mathrm{x}} \mathrm{x}_{\mathrm{e}}\right] \mathrm{x}_{\mathrm{e}}+} \\
& {\left[-\left(\omega_{\mathrm{r}}+\mathrm{v}_{\mathrm{r}}\left(\mathrm{K}_{\mathrm{y}} \mathrm{y}_{\mathrm{e}}+\mathrm{K}_{\theta} \sin \theta_{\mathrm{e}}\right)\right) \mathrm{x}_{\mathrm{e}}+\mathrm{v}_{\mathrm{r}} \sin \theta_{\mathrm{e}}\right] \mathrm{y}_{\mathrm{e}}+} \\
& \frac{\left[-\mathrm{v}_{\mathrm{r}}\left(\mathrm{K}_{\mathrm{y}} \mathrm{y}_{\mathrm{e}}+\mathrm{K}_{\theta} \sin \theta_{\mathrm{e}}\right)\right] \sin \theta_{\mathrm{e}}}{\mathrm{K}_{\mathrm{y}}} \\
= & -\mathrm{K}_{\mathrm{x}} \mathrm{x}_{\mathrm{e}}{ }^{2}-\frac{\mathrm{v}_{\mathrm{r}} \mathrm{K}_{\theta} \sin ^{2} \theta_{\mathrm{e}}}{\mathrm{K}_{\mathrm{y}}}
\end{aligned}
$$




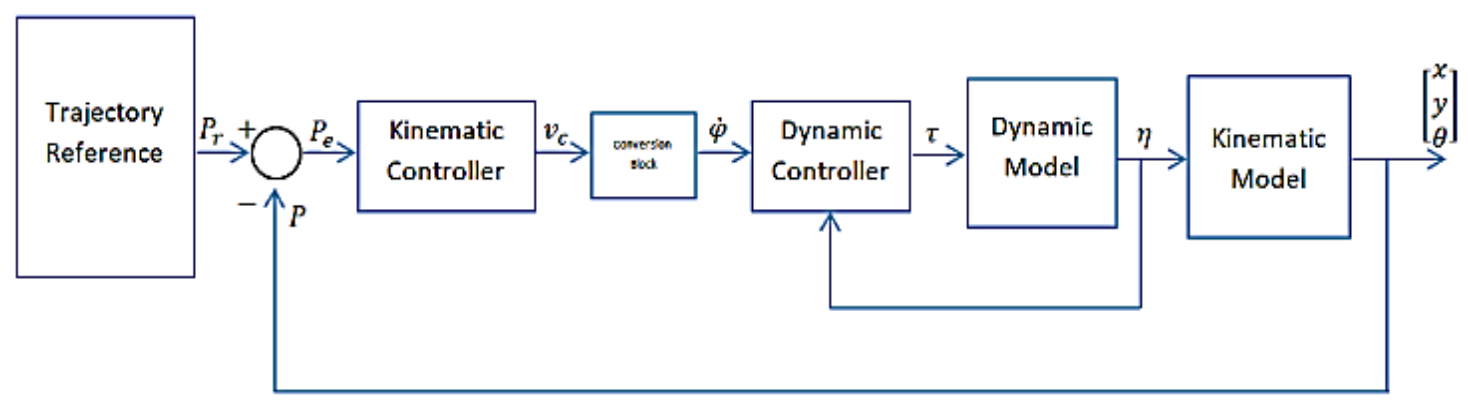

Fig. 2. Trajectory tracking control structure

The kinematic controller design is as follows

$\mathrm{z}_{\mathrm{c}}=\left[\begin{array}{c}\mathrm{v}_{\mathrm{c}} \\ \omega_{\mathrm{c}}\end{array}\right]=\left[\begin{array}{c}\mathrm{v}_{\mathrm{r}} \cos \theta_{\mathrm{e}}+\mathrm{K}_{\mathrm{x}} \mathrm{x}_{\mathrm{e}} \\ \omega_{\mathrm{r}}+\mathrm{K}_{\mathrm{y}} \mathrm{v}_{\mathrm{r}} \mathrm{y}_{\mathrm{e}}+\mathrm{K}_{\theta} \mathrm{v}_{\mathrm{r}} \sin \theta_{\mathrm{e}}\end{array}\right]$

where $\mathrm{K}_{\mathrm{x}}, \mathrm{K}_{\mathrm{y}}$, and $\mathrm{K}_{\theta}$ are design parameter.

\section{2) Dynamic Controller}

In this section a dynamic controller is designed. We consider the following closed loop system in state space describe by

$$
\begin{aligned}
& \dot{\varphi}(\mathrm{t})=\overline{\mathrm{M}} \varphi(\mathrm{t})+\overline{\mathrm{B}}_{\mathrm{u}} \mathrm{u}(\mathrm{t})+\mathrm{B}_{\mathrm{w}} \mathrm{w}(\mathrm{t}) \\
& \mathrm{z}(\mathrm{t})=\mathrm{C} \varphi(\mathrm{t})(12)
\end{aligned}
$$

To design the input constraint, we choose the following Lyapunov function:

$$
\mathrm{V}(\varphi(\mathrm{t}))=\varphi(\mathrm{t})^{\mathrm{T}} \mathrm{P} \varphi(\mathrm{t})
$$

where $\mathrm{P}$ is a positive definite matrix, and the derivative of $\mathrm{V}$ is as follows

$$
\dot{\mathrm{V}}(\varphi(\mathrm{t}))=\dot{\varphi}(\mathrm{t})^{\mathrm{T}} \mathrm{P} \varphi(\mathrm{t})+\varphi(\mathrm{t})^{\mathrm{T}} \mathrm{P} \dot{\varphi}(\mathrm{t})
$$

The stability condition of the closed loop is given by

$$
\left[\begin{array}{cc}
\overline{\mathrm{M}}^{\mathrm{T}} \mathrm{P}+\mathrm{PA}+\mathrm{K}^{\mathrm{T}} \overline{\mathrm{B}}_{\mathrm{u}}{ }^{\mathrm{T}} \mathrm{P}-\mathrm{P}_{\mathrm{u}} \mathrm{K} & \mathrm{PB}_{\mathrm{w}} \\
\mathrm{B}_{\mathrm{w}}{ }^{\mathrm{T}} \mathrm{P} & 0
\end{array}\right]<0
$$

For the application of $\mathrm{H}_{\infty}$ performance, we need to consider this inequality

$$
\dot{\mathrm{V}}(\varphi(\mathrm{t}))+\mathrm{z}(\mathrm{t})^{\mathrm{T}} \mathrm{z}(\mathrm{t})-\gamma^{2} \mathrm{w}(\mathrm{t})^{\mathrm{T}} \mathrm{w}(\mathrm{t})<0
$$

After some manipulation of Schur Complement in Linear Matrix Inequalities, the $\mathrm{H}_{\infty}$ performance becomes

$$
\left[\begin{array}{ccc}
\overline{\mathrm{M}} \mathrm{Q}+\mathrm{Q} \overline{\mathrm{M}}^{\mathrm{T}}-\overline{\mathrm{B}}_{\mathrm{u}} \mathrm{Y}-\mathrm{Y}^{\mathrm{T}} \overline{\mathrm{B}}_{\mathrm{u}}^{\mathrm{T}} & \mathrm{B}_{\mathrm{w}} & \mathrm{QC}_{\mathrm{z}, \mathrm{i}}^{\mathrm{T}} \\
\mathrm{B}_{\mathrm{w}}^{\mathrm{T}} & -\gamma^{2} \mathrm{I} & 0 \\
\mathrm{C}_{\mathrm{z}, \mathrm{i}} \mathrm{Q} & 0 & -\mathrm{I}
\end{array}\right]<0
$$

If matrix $Q>0$, then the system can be stable with disturbance attenuation of $\mathrm{w}(\mathrm{t})$ on the performance output $\mathrm{z}(\mathrm{t})$ less than $\gamma$.
The system in addition to comply the $\mathrm{H}_{\infty}$ performance is also designed so that the input is constrained as:

$$
\|-\mathrm{K} \varphi(\mathrm{t})\| \leq\|\mathrm{u}(\mathrm{t})\| \leq \mathrm{u}_{\max }
$$

To simply the input constraint, the following inequalities from (16) becomes

$$
\begin{aligned}
& \int_{0}^{\mathrm{T}} \mathrm{dV}(\varphi(\mathrm{t}))+\int_{0}^{\mathrm{T}} \mathrm{z}(\mathrm{t})^{\mathrm{T}} \mathrm{z}(\mathrm{t}) \mathrm{dt}-\gamma^{2} \int_{0}^{\mathrm{T}} \mathrm{w}(\mathrm{t})^{\mathrm{T}} \mathrm{w}(\mathrm{t}) \mathrm{dt}<0 \\
& \mathrm{~V}(\varphi(\mathrm{T}))+\int_{0}^{\mathrm{T}} \mathrm{z}(\mathrm{t})^{\mathrm{T}} \mathrm{z}(\mathrm{t}) \mathrm{dt}<\mathrm{V}(\mathrm{x}(0))+\gamma^{2} \int_{0}^{\mathrm{T}} \mathrm{w}(\mathrm{t})^{\mathrm{T}} \mathrm{w}(\mathrm{t}) \mathrm{dt} \\
& \mathrm{V}(\varphi(\mathrm{t})) \leq \mathrm{V}(\varphi(0))+\gamma^{2} \int_{0}^{\mathrm{T}} \mathrm{w}(\mathrm{t})^{\mathrm{T}} \mathrm{w}(\mathrm{t}) \mathrm{dt} \\
& \mathrm{V}(\varphi(\mathrm{t})) \leq \beta
\end{aligned}
$$

Deriving Linear Matrix Inequalities for the input constraint $\mathrm{u}(\mathrm{t})$ can be done as follows

$$
\begin{aligned}
& \|-\mathrm{K} \varphi(\mathrm{t})\| \leq \mathrm{u}_{\max } \\
& \varphi(\mathrm{t})^{\mathrm{T}} \mathrm{K}^{\mathrm{T}} \mathrm{K} \varphi(\mathrm{t}) \leq \mathrm{u}_{\max }{ }^{2} \\
& \frac{1}{\mathrm{u}_{\max }{ }^{2}} \varphi(\mathrm{t})^{\mathrm{T}} \mathrm{K}^{\mathrm{T}} \mathrm{K} \varphi(\mathrm{t}) \leq 1
\end{aligned}
$$

Substitute (19) to (20) will obtain:

$$
\begin{aligned}
& \frac{1}{\mathrm{u}_{\max }{ }^{2}} \varphi(\mathrm{t})^{\mathrm{T}} \mathrm{K}^{\mathrm{T}} \mathrm{K} \varphi(\mathrm{t})-\frac{1}{\beta} \varphi(\mathrm{t})^{\mathrm{T}} \mathrm{P} \varphi(\mathrm{t}) \leq 0 \\
& \varphi(\mathrm{t})^{\mathrm{T}}\left[\frac{\mathrm{P}}{\beta}-\frac{1}{\mathrm{u}_{\max }{ }^{2}} \mathrm{~K}^{\mathrm{T}} \mathrm{K}\right] \varphi(\mathrm{t}) \geq 0 \\
& {\left[\frac{\mathrm{P}}{\beta}-\frac{1}{\mathrm{u}_{\max }{ }^{2}} \mathrm{~K}^{\mathrm{T}} \mathrm{K}\right] \geq 0}
\end{aligned}
$$

Applying Schur Complement, pre-multiplying and post-multiplying Linear Matrix Inequalities with matrix $\mathrm{P}^{-}$ ${ }^{1}$, the (21) becomes

$$
\begin{aligned}
& {\left[\begin{array}{cc}
-\mathrm{Q} & -\mathrm{Y}^{\mathrm{T}} \\
-\mathrm{Y} & -\frac{\mathrm{u}_{\max }^{2}}{\beta}
\end{array}\right]<0} \\
& \text { where } \mathrm{Q}=\mathrm{P}^{-1} \text { and } \mathrm{Y}=\mathrm{KP}^{-1} \text {. }
\end{aligned}
$$

If the Linear Matrix Inequalities is feasible, then the state-feedback gain is

$$
\mathrm{K}=\mathrm{YP}
$$




\section{RESUltS AND ANALYSIS}

In this chapter, several simulations and experimental studies will be performed to determine the effectiveness of the controller designed in the previous section using MATLAB SIMULINK. We tested it with two trajectories, circle trajectory and square trajectory square. The system performance will be tested for each trajectory with external disturbance. We use white noise as disturbance with mean zero and variance 0.001 .

The main physical parameters of a NMR as follows: $\mathrm{m}=12 \mathrm{~kg}, \mathrm{~L}=0.2 \mathrm{~m}, \mathrm{a}=0.05 \mathrm{~m}, \mathrm{R}_{\mathrm{a}}=0.075 \mathrm{~m}, \mathrm{I}_{\mathrm{c}}=$ $5 \mathrm{~kg} . \mathrm{m}^{2}$. The simulation consists in tracking with semimajor axis $20 \mathrm{~m}$ and semi minor axis $0.1 \mathrm{~m}$. The sampling time is chosen as $\mathrm{T}=0.01$ second that implies the Linear Matrix Inequalities optimization problem is solved at each 0.01 second and updated with actual state and actual model.

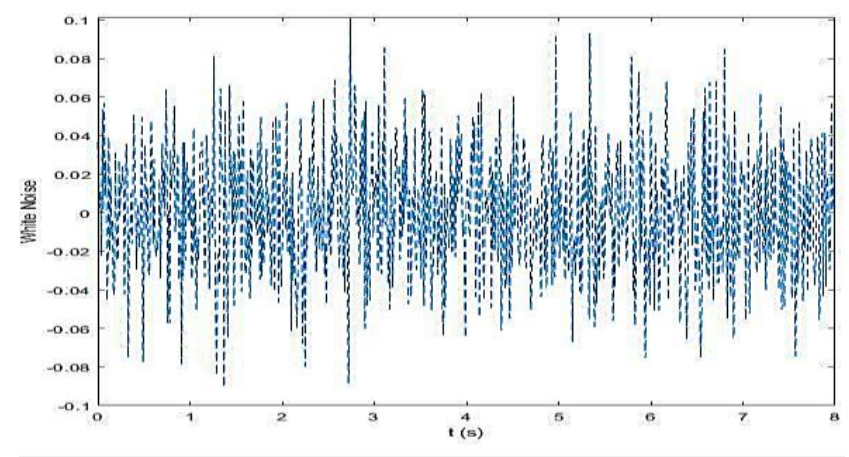

Fig. 3. White noise as disturbance

For the $\mathrm{H}_{\infty}$ performance the torque saturation bound $u_{\max }= \pm 0.6 \mathrm{Nm}$ and we choose $\beta=0.1 \gamma=6.4$. The optimization problem feasible, hence it is guaranteed to respect input constraint.

The variable matrix $\mathrm{P}$ and $\mathrm{Y}$ for the simulation were found as follows respectively:

$$
\begin{aligned}
& P=\left[\begin{array}{cc}
11.9663 & -0.5740 \\
-0.5740 & 1.0438
\end{array}\right] \\
& Y=\left[\begin{array}{cc}
0.4057 & 0.0349 \\
0.0349 & -1.7848
\end{array}\right]
\end{aligned}
$$

and the state-feedback gain is

$$
\mathrm{K}=\left[\begin{array}{ll}
4.8343 & -0.1964 \\
1.4421 & -1.8830
\end{array}\right]
$$

First simulation is performed on a circle trajectory with desired trajectory $x_{r}=19 \sin t$ dan $y_{r}=19 \cos t$ that shows in Fig. 4. The linear velocity is $0.8 \mathrm{~m} / \mathrm{s}$ and the angular velocity is $0.1 \mathrm{~m} / \mathrm{s}$. The results of the control input are shown in the Fig. 5 where the magnitude of the torques are less than $\pm 0.6 \mathrm{Nm}$ and perfect tracking is achieved. Using (18) as input constraint make the steady state of error are close to zero with error leading $0.0068 \mathrm{~m}$ and error lateral $0.0105 \mathrm{~m}$.

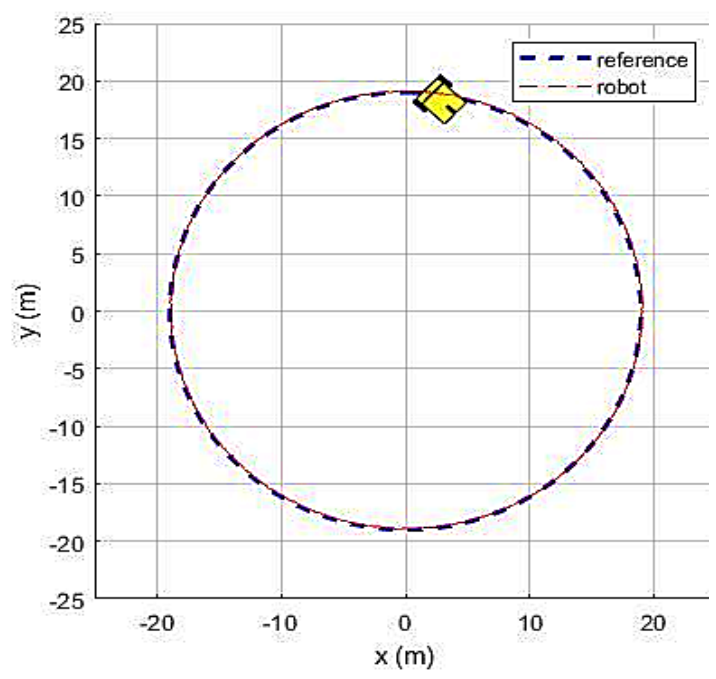

Fig. 4. Circle trajectory with tracking with disturbances

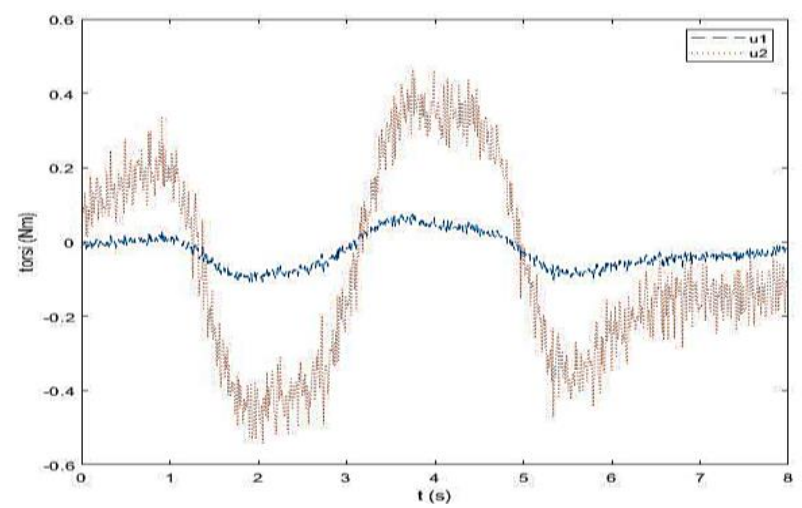

Fig. 5. The torque of circle trajectory

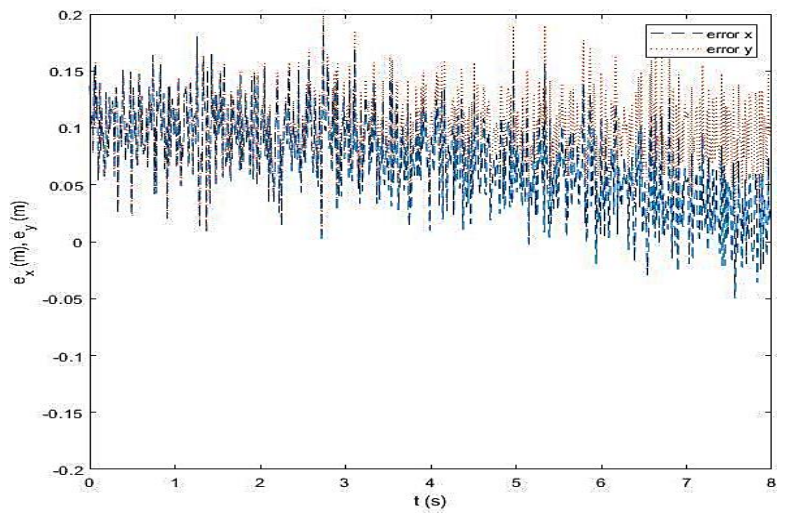

Fig. 6. Error of circle trajectory with disturbance

The second simulation is performed in a square trajectory that shown in Fig. 7. The linear velocity is 0.5 $\mathrm{m} / \mathrm{s}$ and the angular velocity is $0.1 \mathrm{~m} / \mathrm{s}$. The control input on the square trajectory test is shown in Fig. 8 and the control signal magnitudes are still less than $\pm 0.6 \mathrm{Nm}$. The control input oscillates because of the presence white noise as the external disturbance. The tracking error cannot converge to zero which means that there is still an error even though the magnitude is very small. The error leading is $0.0095 \mathrm{~m}$ and error lateral is $0.0106 \mathrm{~m}$. 


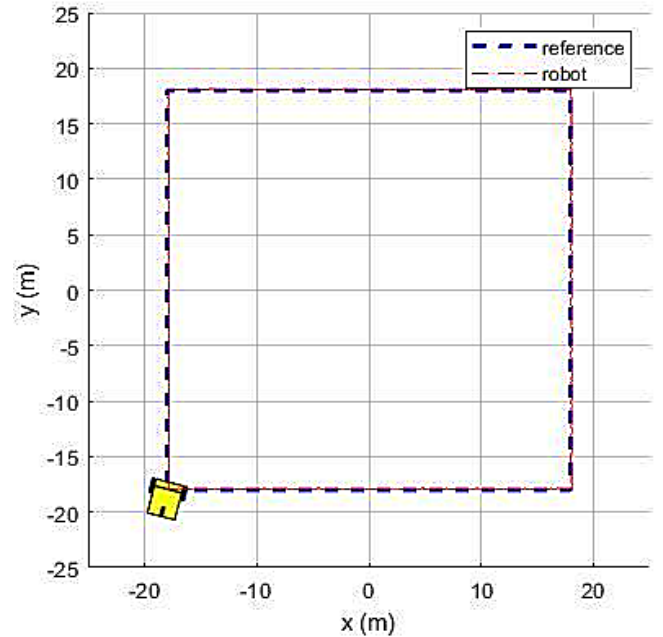

Fig. 7. Square trajectory tracking with disturbances

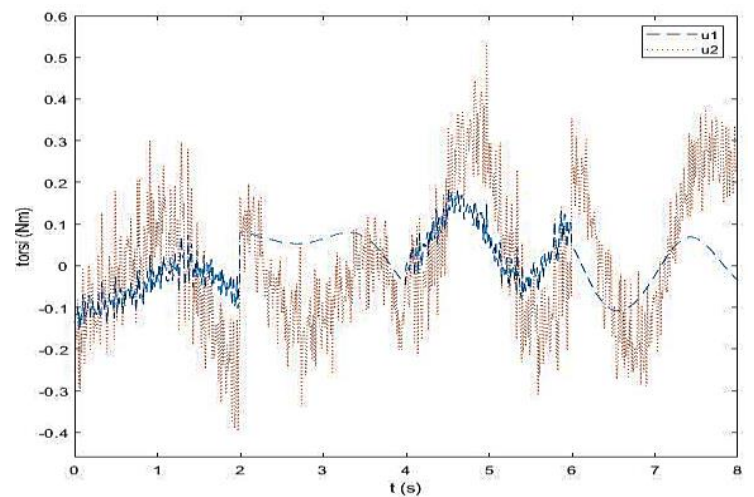

Fig. 8. The torque of square trajectory

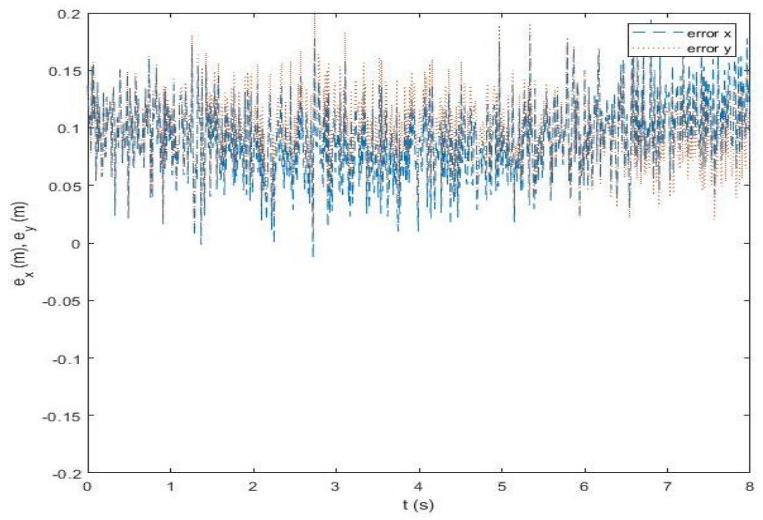

Fig. 9. Error of square trajectory with disturbances

\section{CONCLUSIONS}

In this paper, we have proposed a control system to solve tracking problems in Nonholonomic Mobile Robot (NMR) with input constraint and external disturbance. In order to overcome the input constraint of mobile robot, we designed kinematics controller so that additional speed converges to desired speed and based on dynamics model we designed controller with $H_{\infty}$ performance where Linear Matrix Inequalities optimization is used to solve the inequalities of Lyapunov. Simulations result show that the design controller can perform tracking according to desired trajectory with average tracking error is $0.009 \mathrm{~m}$ and the magnitude of the torques are less than $\pm 0.6 \mathrm{Nm}$.

\section{REFERENCES}

[1] T. C. Lee dan Z. P. Jiang, "Uniform Asymptotic Stability of Nonlinear Switched Systems with An Application to Mobile Robots", IEEE Trans. Automat. Control, Vol. 53, No. 1235-1252, 2008

[2] T. Fukao, H. Nakagawa, dan N. Adachi, "Adaptive Tracking Control of a Nonholonomic Mobile Robot", IEEE Trans. Robot Automat., Vol. 16, No. 609-615, 2000.

[3] S. H. Yu, C. H. Yun, dan H. S. Kang, "Robust Dynamic Surface Tracking Control for Uncertain Wheeled Mobile Robot with Skidding and Slipping" IEEE International Conference on Control and Robotics Engineer, Singapore, 2016.

[4] J. Chang dan Q. X. Meng, "Sliding Mode Control of Trajectory Tracking for Nonholonomic Wheeled Mobile Robots", Control Engineering, Vol. 17, No. 6, 849-852, 2010.

[5] Y. Wang, Z. Miao, H. Zhong, dan Qi Pan, "Simultaneous Stabilization and Tracking of Nonholonomic Mobile Robot: A Lyapunov - Based Approach", IEEE Translation on Control System Technology, Vol. 23, No. 4, 2015

[6] T. C. Lee dan K. T. Song, "Tracking Control of Unicycle-Modeled Mobile Robots Using A Saturation Feedback Controller", IEEE Trans.

[7] S. Wuxi, Y. Junxiong, dan L. Rui, "Linear Active Disturbance Rejection Control for Mobile Robot with Input Saturation", Proceedings of the 37th Chinese Control Conference, 2018.

[8] N. O. Perez-Arancibia, T. C. Tsao, dan J. S. Gibson, "SaturationInduced Instability and Its Avoidance in Adaptive Control of Hard Disk Drives”, IEEE Trans. Control System Technology, 18 (2010) 368-382.

[9] V. Kapila, dan K. Grigoriadis, "Actuator Saturation Control", Automation and Control Engineering, CRC Press, 2002.

[10] J. Huang, C. Wen, W. Wang, dan Z. P. Jiang, "Adaptive Stabilization and Tracking Control of a Nonholonomic Mobile Robot with Input Saturation and Disturbance", Systems \& Control Letters 62 (2013) 234-241.

[11] T. T. Yang, Z. Y. Liu, H. Chen, dan R. Pei, "The Research on Robust Tracking Control of Constrained Wheeled Mobile Robots", Proceedings of the Fourth International Conference on Machine Learning and Cybernetics, Guangzhou, 18-21 August, 2005.

[12] Omid Mohareri, "Mobile Robot Trajectory Tracking Using Neural Networks", Sharjah, UAE, december, 2009.

[13] K. Ogata, "Modern Control Engineering", Prentice-Hall, New Jersey, 1997.

[14] Zhou dan Kemin, "Essentials of Robust Control", New Jersey: Prentice-Hall, may, 1999.

[15] S. Boyd, L. El Ghaoui, E. Feron, dan V. Balakrishnan, "Linear Matrix Inequalities in System and Control Theory", Philadelphia: Society for Industrial and Applied Mathematics, 1994. 